\title{
Review
}

\section{Some p53-binding proteins that can function as arbiters of life and death}

\author{
AW Braithwaite ${ }^{\star, 1}$, G Del Sal ${ }^{2}$ and X Lu ${ }^{3}$ \\ ${ }^{1}$ Department of Pathology, School of Medicine, University of Otago, Dunedin, \\ New Zealand \\ 2 Laboratorio Nazionale Consorzio Interuniversitario Biotecnologie (LNCIB), \\ Area Science Park, and Dipartimento di Biochimica Biofisica e Chimica delle \\ Macromolecole, Università di Trieste, Trieste, Italy \\ ${ }^{3}$ Ludwig Institute for Cancer Research, University College London Branch, \\ London, UK \\ * Corresponding author: AW Braithwaite, Department of Pathology, School of \\ Medicine, University of Otago, Great King Street, Box 913, Dunedin, Otago \\ 9001, New Zealand. Tel: + 6403 4797165; Fax: + 6403479 7136; \\ E-mail: antony.braithwaite@stonebow.otago.ac.nz
}

Received 09.1.06; revised 06.3.06; accepted 06.3.06; published online 31.3.06 Edited by G Melino

\begin{abstract}
Four sets of p53-binding proteins are discussed in this review. These are the E2F family, the ASPP family, Y-boxbinding protein YB1, and the prolyl isomerase Pin1. Each appears to play a role in the decision by $p 53$ to induce an arrest of cell proliferation or apoptosis and they may also be independent markers of cancer. Their activities appear to be linked with the cell cycle and they may also interact with each other. In this review, the properties of each protein class are discussed as well as how they affect $p 53$ functions. A model is proposed as to how their activities might be coordinated. Cell Death and Differentiation (2006) 13, 984-993. doi:10.1038/sj.cdd.4401924; published online 31 March 2006
\end{abstract}

Keywords: p53; E2F; ASPP; YB1; Pin1

\begin{abstract}
Abbreviations: TP53, human p53 gene; CDK, cyclin-dependent kinase; MAPK, mitogen-activated protein kinase; $\mathrm{CHK}$, checkpoint kinase; HIPK2, homeodomain interacting protein kinase 2; UV, ultraviolet light; Ser, serine; Thr, threonine; Pro, proline; Arg, arginine
\end{abstract}

\section{Introduction}

One of the hallmarks of p53 is its propensity to form complexes with other proteins. A list of about 80 p53-binding proteins and family members is shown in Table 1 . This list only includes p53-binding proteins of which two or more independent and in vivo observations of complex formation have been reported. So the list is likely to be much greater. Interactions such as these, as well as post-translational modifications discussed elsewhere in this issue, frequently dictate how p53 behaves. For example, Mdm2 binds to the transactivator domain of p53 to inhibit its transactivation ability and also mediates ubiquitin-dependent proteolysis of p53 (see review by Prives and Hall $^{1}$ ). In contrast, other proteins function as transcriptional coactivators of p53, such as p300/CBP and $\mathrm{Sp} 1^{1}$ or corepressors, again $\mathrm{Sp} 1^{2}$ and $\operatorname{Sin} 3 a,{ }^{3}$ and still others appear to dictate the nature of p53's downstream response. Indeed, a particularly common feature of p53-binding proteins seems to be in determining whether p53 induces a cell cycle arrest or apoptosis.

It is beyond the scope of any review to discuss adequately all of the many different p53-binding proteins, and do them justice. We have therefore concentrated on a few interesting and novel proteins, data about which were discussed at the 12th International p53 Workshop, ${ }^{4}$ and have since been published and which are a focus of our respective laboratories. These proteins appear to influence the decision by p53 to induce apoptosis or cell cycle arrest. The E2F family appears to be critical for normal cell cycle regulation; ASPPS specifically promote p53-dependent apoptosis; YB1 specifically prevents p53-dependent apoptosis; and Pin1 modulates both processes. Although limited in number, these sets of p53-binding proteins nonetheless serve to illustrate the diversity and complexity of the regulation of p53.

\section{The E2F Family}

There are eight members in the E2F family (E2F1-8), all of which are key transcription factors that control cell cycle progression. ${ }^{5}$ The tumor suppressor $\mathrm{pRb}$ (retinoblastoma susceptibility protein) arrests cell cycle progression by binding E2F1, E2F2, and E2F3 and inhibiting their transcriptional activity, whereas p107 binds E2F4 and p130 binds E2F5 to inhibit cell proliferation. ${ }^{6}$

Like pRb, p53 only binds E2F1-3 due to the presence of a conserved domain in the $\mathrm{N}$-terminus, which is not present in the other family members. Moreover, the p53-binding domain in E2F1-3 also binds cyclin A. Hence, cyclin A and p53 can compete for binding to E2F1-3 in vivo. ${ }^{7,8} A$ recent study has shown that the interaction of E2F and p53 is important in regulating the activity of p53 in normal cells throughout the cell cycle. ${ }^{9}$ This is achieved by E2F1-3 binding a region in p53 that overlaps its C-terminal nuclear export sequence (NES), thereby causing p53 to be retained in the nucleus. Furthermore, E2F1 preferentially retains Ser315-phosphorylated p53 in the nucleus although the precise mechanism is unknown. However, one in vitro study has shown that Ser315 phopshorylation can destabilize the p53 tetramer, ${ }^{10}$ thus exposing the NES, thereby increasing the likelihood that p53 will be exported into the cytoplasm. Therefore, the binding of E2F1-3 to p53 could mask the NES, effectively preventing nuclear export.

Ser315 is the only site in p53 that is phosphorylated by kinases that regulate cell cycle progression, for example, 
Table 1 Cellular p53-binding proteins

\begin{tabular}{|c|c|c|c|}
\hline Protein & Function & Protein & Function \\
\hline p300/CBP & Acetylation & IKK alpha & Signalling \\
\hline S100B & Calcium binding & p33ING1 & Signalling \\
\hline $14-3-3$ zeta & Cell cycle & p28ING4 & Signalling \\
\hline 14-3-3 sigma & Cell cycle & JNK1,2 and 3 & Signalling \\
\hline CDC2 & Cell cycle & MAPK & Signalling \\
\hline E4F1 & Cell cycle & PCAF & Signalling \\
\hline Cables & Cell cycle & PKC alpha & Signalling \\
\hline ASPP2/53BP2 & Cell cycle & PKR & Signalling \\
\hline HSP90A & Chaperone & STE20 like kinase MST1 & Signalling \\
\hline HMG1 & Chromatin & VRK1 & Signalling \\
\hline Vimentin & Cytoskeleton protein & Nucleolin & Structural \\
\hline Rad51 & DNA-binding protein & AMF1 & Transcription \\
\hline RecQ protein like 3 & DNA-binding protein & CCAAT-binding factor & Transcription \\
\hline RPA & DNA-binding protein & DNA topoisomerase I & Transcription \\
\hline BRCA1 & DNA repair & DNA topoisomerase II alpha & Transcription \\
\hline BRCA2 & DNA repair & HSF3 & Transcription \\
\hline MDC1 & DNA repair & Securin & Transcription \\
\hline Ref-1 & DNA repair & PML & Transcription \\
\hline Pin1 & Prolyl isomerase & RNA polymerase II EF & Transcription \\
\hline PTEN & Lipid phosphatase & Sin $3 A$ & Transcription \\
\hline ER alpha & Nuclear receptor & Sp1 & Transcription \\
\hline Mot-2 & Oncogene & TAF9 & Transcription \\
\hline Nucleostemin & Oncogene & WT1 & Transcription \\
\hline HIF1 alpha & Oxidative stress & ZBP89 & Transcription \\
\hline WOX1 & Oxidoreductase activity & TRAP220 & Transcription \\
\hline Ribonucleotide reductase & Reductase & p53BP1 & Transcription \\
\hline Mdm2 & Regulation & YB-1 & Transcription \\
\hline MdmX & Regulation & SMN1 & Translation \\
\hline $\mathrm{ABL}$ & Signalling & p63, p73 & Tumor supressors \\
\hline ATM & Signalling & SUMO1 & Sumoylation \\
\hline $\mathrm{CHK} 1,2$ & Signalling & NEDD45 & Neddylation \\
\hline CK1 alpha & Signalling & E2-25K & Ubiquitylation \\
\hline CDK2,5,7 & Signalling & E2A & Ubiquitylation \\
\hline DNAPK & Signalling & UBE3A & Ubiquitylation \\
\hline ERK1,2 & Signalling & HAUSP & Ubiquitylation \\
\hline GSK3 beta & Signalling & Zinc-finger protein 363 & Ubiquitylation \\
\hline
\end{tabular}

This table contains a list of p53-binding proteins for which two or more independent and in vivo confirmations have been reported. Viral p53-binding proteins have been excluded. It has been constructed from information in Prives and Hall ${ }^{1}$ and Keller et al. ${ }^{80}$ from the Human Protein Reference Database (http://www.hprd.org) and the Biomolecular Interaction Network Database (http://www.bind.ca/).

cyclin A/cyclin-dependent kinase (CDK)2, ${ }^{11,12}$ cyclinB/ CDK $1,{ }^{12}$ and aurora kinase. ${ }^{13}$ As a consequence, the phosphorylation status of p53 Ser315 is periodic and regulated throughout cell cycle. Interestingly, the expression of E2F1-3 and cyclin A are precisely regulated during the cell cycle (reviewed in Loughan and La Thangue ${ }^{6}$ ). The levels of E2F are high at the $G_{1} / S$ transition, ${ }^{14,15}$ whereas cyclin $A$ is high at mid-S to $G_{2} / M{ }^{16}$ As cyclin A competes with p53 for binding to E2F1-3, ${ }^{8} \mathrm{E} 2 \mathrm{~F}$ has a window of opportunity to regulate $p 53$ at the $\mathrm{G}_{1} / \mathrm{S}$ transition when $\mathrm{E} 2 \mathrm{~F} 1-3$ levels are high and the cyclin $A$ and Ser315-phosphorylated p53 are relatively low. It is also when $\mathrm{p} 21^{\text {Waf1/Cip } 1}$ is required to perform its $G_{1}$ checkpoint function, although in excess will cause cell cycle arrest. In agreement with this, expression of p2 $1^{\text {Waf } 1 / C i p 1}$ is highest at the $G_{1} / S$ transition and lowest in $S$ phase. ${ }^{17}$ In addition, nuclear p53 has only been detected in untransformed cells at the $\mathrm{G}_{1} / \mathrm{S}$ transition, while cytoplasmic p53 is associated with $S$ phase cells, and cells expressing high levels of cyclin $A .{ }^{18}$ The striking similarity of the timing between $\mathrm{p} 21^{\text {Waf1/Cip } 1}$ and E2F expression is consistent with the notion that E2F/p53 interactions play a role in regulating the transcriptional activity of p53 throughout the cell cycle. Hence, by binding and retaining Ser315 phosphorylated p53 in the nucleus, E2F1-3 act as fine tuners for p53 during cell cycle progression. ${ }^{9}$ This cyclic regulation of p53 by E2F family members is illustrated in Figure 1.

One of the most common events occurring in human cancer is the inactivation of the $R B$ pathway. This is often achieved by mutations in $\mathrm{pRb}$ and $\mathrm{p} 16^{\text {Ink4a }}$, a CDK inhibitor, reduced expression of $\mathrm{p} 27^{\mathrm{Kip} 1}$, and overexpression of various cyclins and CDKs. These result in elevated activities of E2F and cell cycle entry. Interestingly, the E2F/p53 complex has been detected in tumor cells and a previous study showed that the cyclin A binding domain of E2F1-3 is required to stimulate the apoptotic function of $\mathrm{p} 53$. $^{8}$ This is particularly important as it has been shown that the ability of E2F1 to enhance the apoptotic function of $\mathrm{p} 53$ is independent of $\mathrm{p} 19^{\mathrm{Arf}},{ }^{19}$ which is a transcriptional target of $\mathrm{E}_{2} \mathrm{~F}^{20}$ and is also an inducer of p53 through its ability to prevent Mdm2-mediated degradation of p53. ${ }^{21}$

In the context of DNA damage, E2F is also important. In response to a genotoxic event, p53 causes a cell cycle arrest by transactivating the $C D K N 1 A$ gene, encoding $\mathrm{p} 21^{\text {Waf1/Cip } 1}$ thereby ensuring $a G_{1}$ arrest. Almost all DNA-damaging signals that activate p53 also induce expression of E2F1.22 This results in the increase of E2F-p53 complexes occurring while cyclin A expression is low, thereby allowing E2F1 to enhance the apoptotic function of $p 53 .^{8}$ This could be one of 


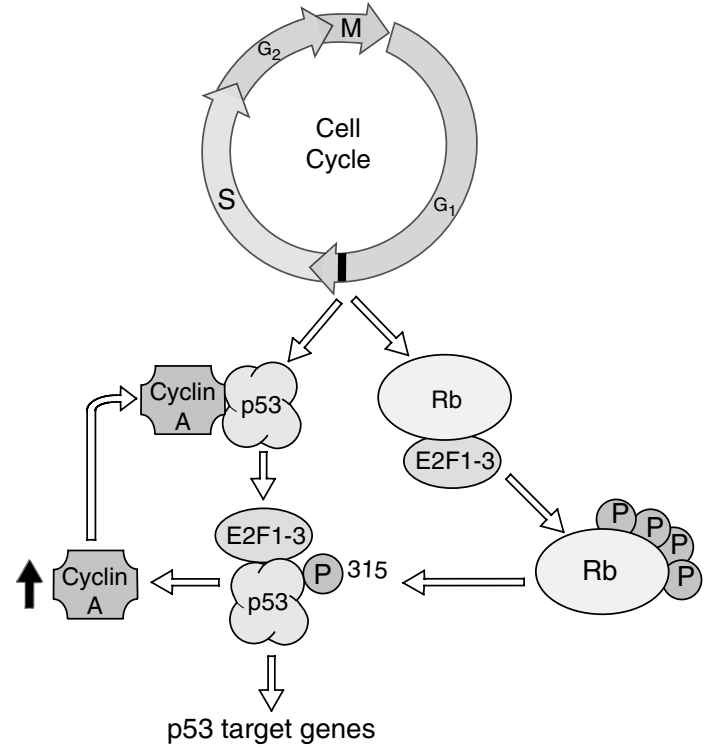

Figure 1 Cyclic control of p53 cell cycle checkpoint function by E2F family members. p53 becomes phosphorylated at ser315 by cell cycle-associated kinases. This provokes E2F1-3 to bind p53 displacing cyclin A interaction and inducing p53 to become transcriptionally competent. As cyclin A and other kinase levels increase, E2F1-3 binding will be disrupted thereby reducing p53 activity

the molecular explanations as to why tumor cells are frequently more sensitive to p53-induced apoptosis. ${ }^{23}$ Notwithstanding this, E2F1 may well participate directly in a DNA damage response to regulate apoptosis, independently of $p 53 .^{24}$

\section{The ASPP Family}

Among the factors identified so far, the evolutionarily conserved ASPP family of proteins plays an important role in regulating the apoptotic, but not cell cycle function of p53. The ASPP family has three members - ASPP1, ASPP2, and inhibitory (i) ASPP. All ASPP family members share sequence similarity in their $\mathrm{C}$-terminals that contain the signature sequences - Ankyrin repeats, $\mathrm{SH} 3$ domain, and Proline-rich region - hence, ASP Protein. ASPP also stands for apoptosis stimulating protein of $\mathrm{p} 53$ as all of them can bind and regulate the activities of $p 53$ through their C-terminus. ${ }^{25}$

The most conserved member of the ASPP family is iASPP and it is the only member of the ASPP family that exists in Caenorhabditis elegans. ${ }^{26}$ Deletion of iASPP and p53 in C. elegans has shown that IASPP is an important antiapoptotic gene product that prevents germ cells from DNA damageinduced apoptosis, which to a large extent is p53 dependent. To our knowledge, iASPP is one of the most conserved inhibitors of p53 identified so far. Mechanistically, iASPP binds and inhibits p53-mediated apoptosis through its C-terminus. Remarkably, the ability of iASPP to inhibit p53mediated apoptosis is conserved from $C$. elegans to humans, as C. elegans iASPP can inhibit human p53-induced apoptosis in human cells as effectively as human iASPP. ${ }^{26}$

Humans have evolved two ASPP family members, ASPP1 and ASPP2, both of which bind to p53 due to the sequence

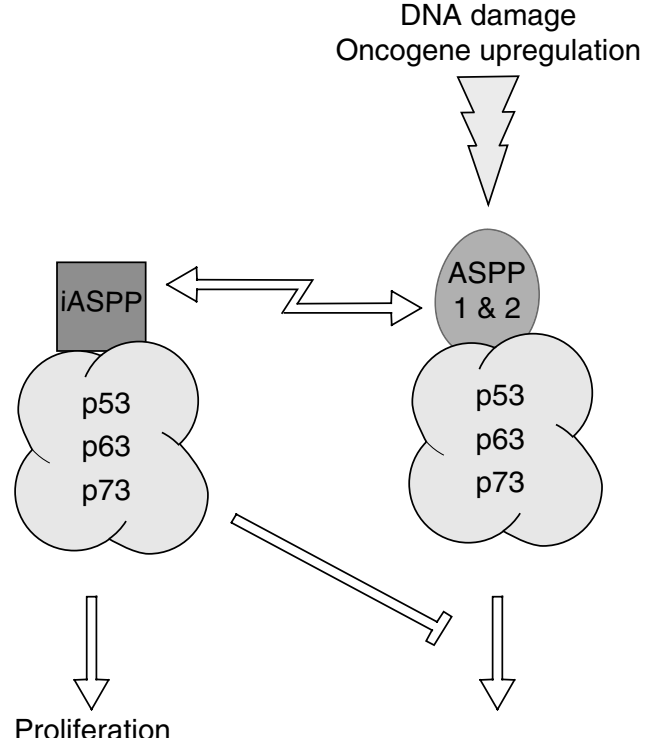

Proliferation
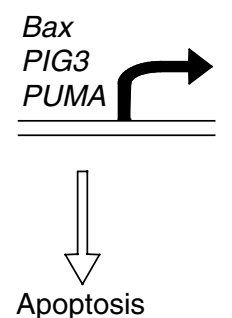

Figure 2 Regulation of p53-dependent apoptosis by ASPP family members. DNA damage or oncogenic stimulation activate ASPPs to interact with p53 family members. This directs them specifically to proapoptotic gene promoters resulting in cell death. Inhibitory ASPP (iASPP) prevents this occurring, thus allowing cell proliferation to occur

similarity in their $\mathrm{C}$-terminus, and stimulate the apoptotic function of p53. However, the N-terminus of ASPP1 and ASPP2 is still required for the proapoptotic function of ASPP1 and ASPP2. ${ }^{25}$ While the N-terminals of ASPP1 and ASPP2 are very similar, they share no sequence similarity with that of iASPP. ${ }^{27}$

The precise details underlying the mechanism of the proapoptotic function of the N-terminus of ASPP1 and ASPP2 are currently unknown. Nevertheless, when intact ASPP1 or ASPP2 binds p53, they can specifically enhance the ability of p53 to induce apoptosis but not cell cycle arrest. Chromatin immunoprecipitation assays have shown that the binding of ASPP1 and ASPP2 to p53 can selectively stimulate the binding of p53 to promoters of the proapoptotic genes, such as $B A X$ and PIG3, but not to the promoters of the cell cycle arrest gene $C D K N 1 A$ or the MDM2 gene. ${ }^{25}$ Similarly, the binding of ASPP1 and ASPP2 to the p53 family members, p63 and p73, also enhance the apoptotic function of p63 and p73 by selectively stimulating their transcriptional activities on proapoptotic promoters 28 (Figure 2).

Oncogenes, such as RAS and E1A, can transform rat embryo fibroblasts in vitro but they can also induce expression of p53 through the ability of their protein products to induce p14 $4^{\text {Arf }}$ and inhibit Mdm2-mediated degradation of p53. ${ }^{29}$ In addition, E1a can increase the activity of E2F through its 
ability to bind $\mathrm{pRb}$. Both $R A S$ - and E1A-transformed cells tend to be sensitive to p53-mediated apoptosis. Hence, inhibiting the apoptotic function of p53 is one of the most important steps during oncogenesis. Consistent with the notion that the expression levels of the ASPP family members, ASPP1, ASPP2 and iASPP, play a key role in determining the cellular apoptotic response of p53, p63, and p73, coexpression of ASPP1 and ASPP2 inhibit, whereas coexpression of iASPP enhances the transforming activities of oncogenes $R A S$ and $E 1 A .{ }^{26}$ In addition, high levels of ASPP1 and ASPP2 are not tolerated in cells since attempts to establish cell lines stably expressing ASPP1 and ASPP2 have been unsuccessful (X Lu, unpublished data). In agreement with this, antisense RNA of ASPP1 and ASPP2 reduced apoptosis induced by DNAdamaging agents including chemotherapeutic drugs cisplatin, etoposide, and UV. This was observed in tumor cells expressing either wild-type $p 53^{25}$ or no p53. ${ }^{26}$ In contrast, no difficulties were encountered in establishing cell lines stably expressing high levels of iASPP, which are more resistant to apoptosis induced by cisplatin or UV compared to their parental cell lines. ${ }^{26}$ These data serve to illustrate that whereas ASPP1 and ASPP2 are potential tumor suppressors, iASPP is likely to be an oncoprotein.

This hypothesis is supported by findings obtained from the co-crystal structure between the DNA-binding domain of p53 and the C-terminus of ASPP2, that all ASPP2 contact residues in $\mathrm{p} 53$ are mutated in human cancer with a relatively high frequency. ${ }^{30}$ Among them, the most studied residue is Arg181, a mutation that occurs in human breast and cervical carcinoma cells. ${ }^{31}$ It is also a mutant p53 that can induce cell cycle arrest as effectively as wild-type p53 through its competence to transactivate the promoter of the CDKN1A gene. ${ }^{31}$ The only defect observed with this p53 mutant is its failure to transactivate the promoter of the $B A X$ gene and to induce apoptosis. ${ }^{31}$ Interestingly, when Arg181 is mutated to cysteine or leucine, the resultant p53 mutants have reduced ability to bind ASPP1. These mutant $p 53$ proteins are also defective in responding to the stimulatory effects of ASPP1 and ASPP2. ${ }^{25}$ Hence, escaping the stimulatory function of ASPP1 and ASPP2 may be one of the underlying reasons why all ASPP2 contact residues are mutated in human cancers.

Finally, the importance of the ASPP family in human malignancies is underscored by the observation that downregulation of ASPP1 and ASPP2 is a frequent event in human tumors expressing wild-type p53, and to a lesser extent, in tumor cells expressing mutant p53. ${ }^{25}$ This could be due to the fact that ASPP1 and ASPP2 are common activators of p53. Overexpression of iASPP is also detected in various tumor cells. ${ }^{26}$ These data illustrate that the ASPP family of proteins may play a key role in tumor development, particularly those with a genetically wild-type TP53. Therefore, the ASPP family presents an attractive molecular target for therapeutic development.

\section{The Y-box-binding Protein YB1}

Y-box-binding protein YB1, also known as DNA-binding protein $(\mathrm{dbpB})$ and nuclease-sensitive protein 1 (NSEP1), encoded by the NESP1 gene, is a member of the cold shock family of proteins that contain a highly conserved nucleic acidbinding motif (reviewed in Kohno et al. ${ }^{32}$ ). The name Y-box refers to a specific DNA sequence to which all $Y$-box family members bind and is very similar to the common CCAAT box. ${ }^{33}$ Two homologues have also been identified, $\mathrm{dbpA}$ and $\mathrm{dbpC}^{32} \mathrm{DbpC}$ is the human homologue of the mouse $\mathrm{Y}$-box protein MSY2 that is expressed only in germ cells and is essential for sperm and follicle development. ${ }^{34,35}$ The mouse homologue of YB1 is MSY1, which is associated with paternal mRNA in spermatocytes. ${ }^{36}$ Thus, YB1 and its family members probably play important roles in embryonic development.

YB1 appears to carry out multiple functions including roles in RNA splicing and masking, translation, DNA repair, and transcription (reviewed in Kohno et al. ${ }^{31}$ and Wolffe ${ }^{33}$ ). For nuclear activities, YB1 must first translocate to the nucleus, as the majority of YB1 is located in the cytoplasm. ${ }^{37}$ Thus, the regulation of nuclear translocation is an important control of YB1 function. Nuclear translocation of YB1 occurs in response to a variety of stresses that include UV exposure, DNA-damaging agents, and hypothermia. ${ }^{37-39}$ Recent evidence suggests that YB1 must first be cleaved, and that only the $\mathrm{N}$-terminal portion translocates to the nucleus. ${ }^{40}$ This issue is discussed further below.

YB1 is also an important marker of and contributor to tumorigenesis. YB1 expression in clinical specimens is significantly correlated with tumor stage and patient prognosis for many human tumors, including the common malignancies of the lung, breast, and colorectum. ${ }^{32,41,42}$ Indeed, one study reported no expression of YB1 in normal breast tissue, ${ }^{41}$ making YB1 a tumor-specific marker. Moreover, stratification of YB1 staining by subcellular localization has shown that nuclear YB1 is generally associated with more advanced disease and poorer patient prognosis. ${ }^{32}$ Overexpression of YB1 is also frequently observed in drug-resistant cells and tumors and its expression is closely associated with that of $P$ glycoprotein encoded by the Multidrug Resistance 1 (MDR1) gene. $^{32}$

In addition to this circumstantial evidence, recent experimental studies have confirmed the importance of YB1 in cancer. Expression cloning identified YB1 as a factor conferring epidermal growth factor (EGF) independence on mammary epithelial cells, and transduction of YB1 into such cells caused the EGF receptor to be overexpressed. ${ }^{43}$ EGF receptor upregulation is a marker that is frequently linked to poor outcome in breast cancer patients. ${ }^{44}$ In addition, transgenic mice overexpressing YB1 in a breast-specific manner were found to be highly tumor prone ${ }^{45}$ and tumor cells derived from these mice were genetically unstable. A direct link between nuclear localization and growth-promoting activities of $\mathrm{YB} 1$ has also been shown. ${ }^{46}$ Transduction of MCF-7 cancer cells with YB1 led to clonal expansion in softagar, which was prevented if nuclear translocation was abolished by mutation. This mutation, at serine 102, also abolished Akt-dependent phosphorylation of YB1.

YB1 also binds to p53. This occurs through an interaction with the C-terminus between amino-acid residues 363-376, ${ }^{47}$ a region that is extensively modified, and which, at least in vitro is important in regulating p53 function (see elsewhere in this issue). Inhibition of YB1 has been shown to upregulate p21 $1^{\text {Waf1/Cip } 1}$ expression, ${ }^{47}$ although in a separate study, 
inhibition of YB1 led to p53-dependent apoptosis in several human cancer cell lines. ${ }^{48}$ The reported antiapoptotic activity $^{49}$ of $\mathrm{p} 21^{\text {Waf1/Cip } 1}$ would seem to be inconsistent between these two sets of observations.

YB1 nuclear translocation may also involve p53. As discussed above, nuclear translocation of YB1 occurs after stress treatment of cells, and we showed that this required expression of wild-type p53. ${ }^{50,51}$ These studies also demonstrated that the translocation does not result from direct binding to p53, but requires that the p53 protein is transcriptionally competent. ${ }^{50}$ Thus, it seems likely that p53 induces expression of a gene, the protein product of which would bind YB1, and effect its nuclear translocation.

Notwithstanding these observations, nuclear translocation of YB1 has been shown to occur in a cell cycle stagedependent fashion, occurring only at the $G_{1} / S$ phase boundary, ${ }^{52}$ that it is dependent on binding to the splicing factor SRp30c, ${ }^{53}$ and as mentioned above, it requires Aktdependent phosphorylation. ${ }^{46}$ Rationalization of these separate observations has yet to occur, but an association with cell cycle stage could be a possible link.

Once in the nucleus, YB1 can stimulate cell proliferation and transactivate several 'growth' genes including EGFR, ${ }^{43}$ $C$-ERB $B 2,{ }^{54}$ and the gene encoding DNA polymerase $\alpha,{ }^{55}$ and downregulate cell death-promoting genes $F A S^{56}$ and TP53. ${ }^{48}$ In addition, it was recently reported that nuclear YB1 prevents $\mathrm{p} 53$ from inducing apoptosis by selectively preventing p53 from transactivating proapoptotic genes. ${ }^{50}$ Thus, YB1 acts in an opposite manner to ASPP proteins. This inhibitory activity of YB1 does require a direct interaction with p53. ${ }^{50}$

Thus, putting these data together (Figure 3) one might envisage a scenario in which YB1 carries out activities in both the nucleus and the cytoplasm that are a part of normal cell physiology and which prevent premature senescence. ${ }^{57}$ Upon stress or other exogenous signals such as certain growth factors, YB1 becomes phophorylated by Akt. This might provide a signal for proteolytic cleavage of YB1. In parallel, these signals also 'activate' p53, which causes cell cycle arrest and induces expression of gene $X$. The product of this gene would then bind to the N-terminal portion of YB1 and mediate its translocation to the nucleus. Once in the nucleus, YB1 can promote growth and inhibit apoptosis.

Presumably, nuclear translocation of YB1 represents an adaptive response to stress. However, if the stresses become chronic, YB1 may confer a growth advantage on cells, which would predispose them to malignant transformation. Continued expression of nuclear YB1 may also be important for continued tumor cell growth.

\section{The Prolyl Isomerase Pin1}

The prolyl isomerase Pin1 is a different kind of p53-binding protein. In contrast to the other proteins discussed thus far, it is an enzyme that catalyses phosphorylation-directed prolyl isomerization. However, similar to the others, it again contributes to maintaining the balance between p53-dependent proliferative and proapoptotic pathways in normal cells.

Pin1 catalyzes cis/trans isomerization at phosphorylated Ser-Pro or Thr-Pro motifs present in many proteins involved in
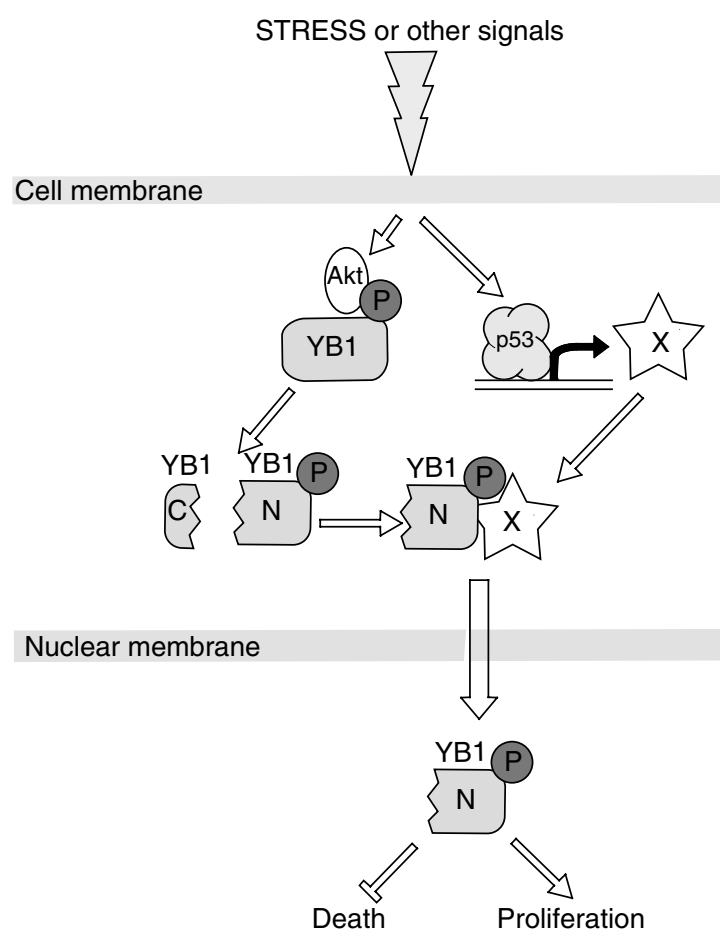

Figure 3 A role for $p 53$ in the regulation of YB1 nuclear translocation. Stress treatment of cells as well as other signals results in Akt-mediated phosphorylation of YB1 and proteolytic cleavage. The N-terminal fragment associates with a p53 target gene product $(X)$ where upon the complex migrates to the nucleus. Nuclear YB1 then promotes cell proliferation and inhibits cell death by modulating gene transcription

tumorigenesis, such as cyclin D1, b-catenin, NF- $\kappa \mathrm{B}, \mathrm{p} 53$, and p73. ${ }^{58}$ The resulting conformational changes can trigger various functional outcomes, thereby regulating a multitude of profoundly interconnected cellular processes. ${ }^{59}$ Substrate recognition by Pin1 follows phosphorylation by prolinedirected kinases, including CDKs and MAPKs, while Pin1 is itself induced by a variety of proliferative and oncogenic signals. ${ }^{58}$ At the molecular level, one possible mechanism of Pin1 activity is to 'lock' some of its substrates in a phosphorylated cis-conformation. Although energetically unfavorable, it is resistant to dephosphorylation and degradation induced by trans-specific phosphatases and ubiquitin ligases, resulting in stable and active proteins. ${ }^{58}$ Other substrates such as c-Myc are instead isomerized to a trans-conformation and their stability decreases as a result of Pin1 activity. ${ }^{60}$

Accumulating evidence indicates that, upon phosphorylation, Pin1 regulates the timing of $p 53$ activation by rendering p53 suitable for subsequent modifications and modulating its interaction with DNA and cofactors (Figure 4). Barely detectable under normal growth conditions, the interaction between p53 and Pin1 markedly increases after genotoxic stress, on expression of activated oncogenes, and probably in response to a wide range of other stimuli (see above references). These events cause phosphorylation of a subset of the six Ser/Thr-Pro motifs of p53 (within the N-terminal polyproline domain of p53) allowing them to bind the $\mathrm{N}$ terminal WW domain of Pin1, with subsequent isomerization by its $\mathrm{C}$-terminal catalytic domain. UV irradiation or treatment 

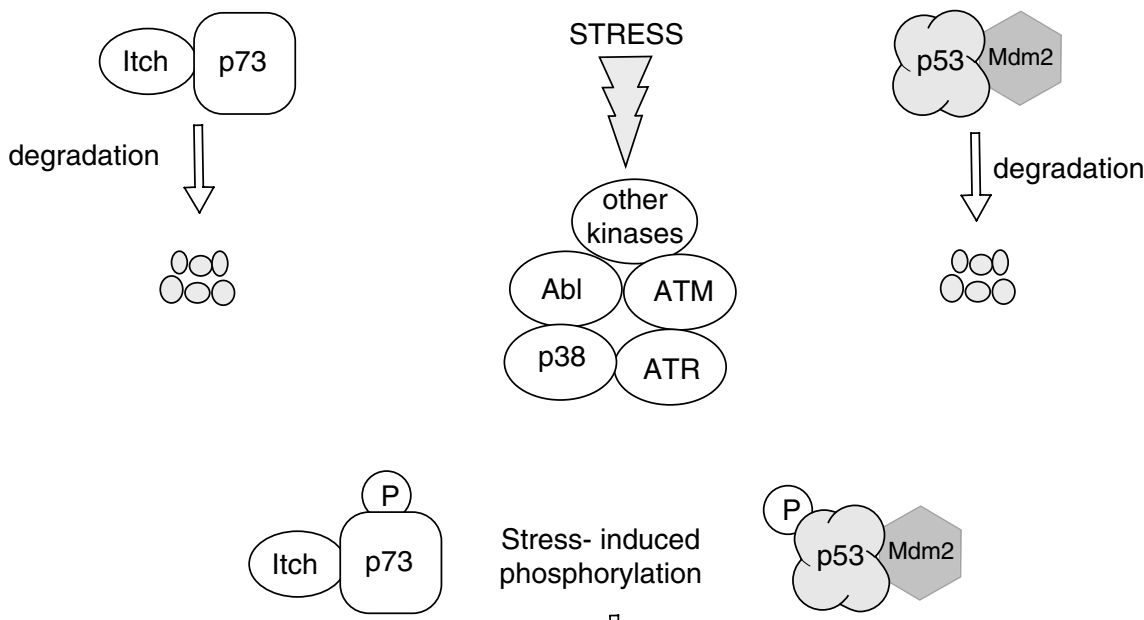

Stress- induced phosphorylation
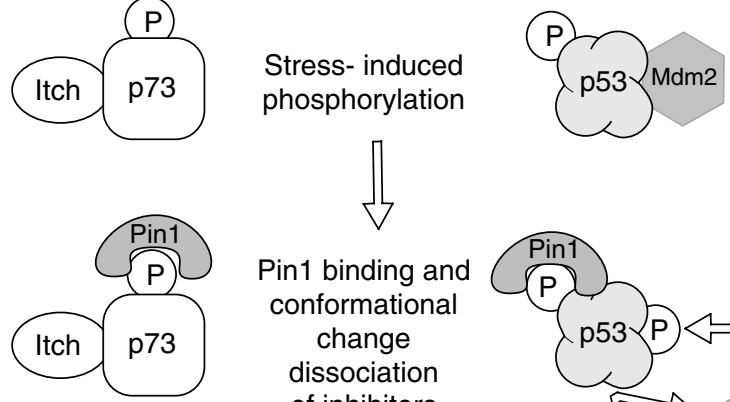<smiles>C=CC=C</smiles>

Pin1 binding and conformational

change

dissociation

of inhibitors and stablization
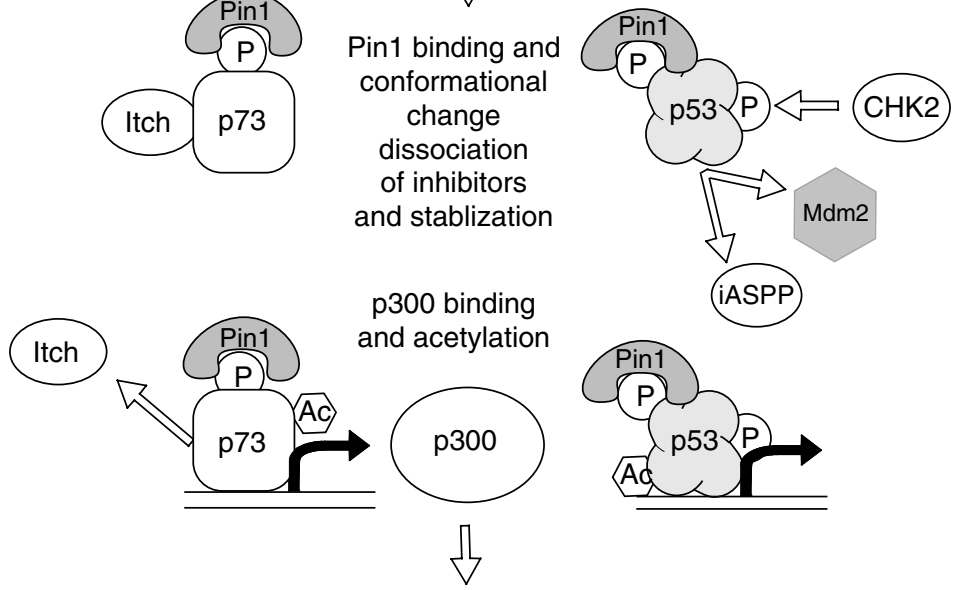

Increase in

transcriptional activity

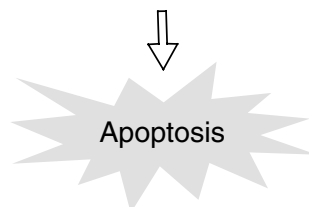

Figure 4 Phosphorylation-dependent prolyl isomerization catalyzed by Pin1 regulates the timing of $\mathrm{p} 53$ and $\mathrm{p} 73$ activation upon stress. Under normal conditions, both p53 and p73 are targeted for degradation by their ubiquitin ligases, primarily Mdm2 and Itch. Following genotoxic stress, and possibly also after other signaling events, activation of cellular kinases stimulates the phosphorylation-dependent association of $\mathrm{p} 53$ and p73 with Pin1. This event results in conformational changes that promote subsequent modifications: p53 is phosphorylated by CHK2 and dissociates from Mdm2, while association with p300 promotes p73 stabilization. This could possibly also result from Pin1 - dependent dissociation of Itch (see text for details). Finally, Pin1 stimulates acetylation of p53 and p73 by p300 and dissociation from the inhibitor iASPP, thus enhancing the transcriptional activity of p53 and p73 towards proapoptotic target genes

of cells with doxorubicin recruits Pin1 to Ser33, Thr81, and Ser315 of p53, while $\gamma$-irradiation also requires Ser46. ${ }^{61,62}$ Therefore, Pin1 can integrate multiple signals deriving from different pathways, thus fine-tuning p53 activity. Cells lacking Pin1 fail to efficiently stabilize p53 upon genotoxic stress and, as a consequence, cell cycle arrest and apoptotic responses are not fulfilled. ${ }^{58,62}$

Extensive work is still needed to clarify which phosphorylation events are important in different circumstances, and how Pin1 activity at different Ser/Thr-Pro sites impinges on the overall conformation of p53. However, the importance of Pin1 binding to Thr81-Pro82 of p53 is emphasized by the fact that this site is found mutated in tumors, ${ }^{63}$ and recent work has demonstrated that Pin1 activity at Pro82 is essential for the binding of $\mathrm{CHK} 2$ and Ser20 phosphorylation upon DNA damage, thereby allowing efficient detachment from Mdm2. ${ }^{64}$ These observations are in agreement with previous demonstrations that Pin1 is required for dissociation of Mdm2 and full stabilization of p53 following UV irradiation. ${ }^{62}$ As a matter of fact, the contribution of Pin 1 to the induction of p53 target genes ${ }^{62}$ could be partly explained by the observation that Mdm2 is also able to inhibit p53 transcriptional activity by 
catalyzing its NEDDylation. ${ }^{65}$ It will be interesting to determine whether Pin1 activity can also affect the pathways, yet elusive, which engage the p53 DNA-binding domain with the ubiquitin ligases Pirh2 and COP1. ${ }^{66,67}$

p53 transcriptional activity is also regulated by interaction with acetyltransferases and stress-activated isomerization of p53 stimulates the acetylation of p53 C-terminal lysine residues by $\mathrm{p} 300 / \mathrm{CBP}$ ( $\mathrm{G}$ Del Sal, unpublished data), analogous to $p 73 .^{68}$ Furthermore, these events have been linked to the induction of proapoptotic target genes. ${ }^{69}$ Understanding how Pin1-induced conformational shifts affect the interaction of p53 with some of its partners and modulating its functions, may help us explain the specificity of the p53 response.

It is widely accepted that the cell type, the nature of the stress, and its intensity determine the final outcome of p53's activities. A role for Pin1 in determining p53's choice between inducing cell cycle arrest or apoptosis has been proposed, based on the observation that in cells devoid of prolyl isomerase activity, the induction of apoptotic p53 targets is compromised. ${ }^{62}$ Intriguingly a key Pin1 target site at Ser46, which is phosphorylated by p38 MAPK and HIPK2, is central for modulating p53 apoptotic function. ${ }^{70,71}$ Pin1-induced conformational change on Ser46 may be needed to reach the p53 dosage necessary for switching on this subset of genes. Alternatively, Pin1 activity could ameliorate occupancy of p53 proapoptotic promoters. For instance, interaction with ASPP proteins directs p53 (and also p63 and p73) towards proapoptotic promoters. ${ }^{25,28}$ Recent work (X Lu, unpublished data) has indicated that the Pro/Arg 72 polymorphism also influences ASPP binding, implying a critical role for the conformation of the p53 proline-rich domain in the apoptotic response that invites speculation on the role of proline isomerization.

The role of p53 family members p73 and p63 in regulating p53 apoptotic function has still not been clarified. In some contexts, p63 and p73 are required for recruitment of p53 on pro-apoptotic target promoters. ${ }^{72}$ It has also been demonstrated that the prolyl isomerase activity of Pin1 modifies p73 conformation, promoting its acetylation by $\mathrm{p} 300 / \mathrm{CBP}$ in a cAbl-dependent fashion, and indeed under genotoxic stress, Pin1 is essential for p73's apoptotic activity. ${ }^{68}$ This finding has important implications for cancer therapy, given p73's ability to determine chemosensitivity in some tumor cells lacking functional $\mathrm{p} 53,{ }^{73}$ and also implicates Pin1 in coregulating p53 family members' activities. The evidence that Pin1 is present at p53 and p73-target promoters (G Del Sal, unpublished data) suggests that Pin1 may contribute to promoter selection by stabilizing transcriptional complexes involving p53, p63, p73, and coactivators like p300, ASPP, and others. The polyproline region of $p 73$ that is recognized by Pin1 does in fact overlap with the binding site for YAP, an essential factor directing p73 towards proapoptotic promoters. $^{74}$ Intriguingly, conformational alteration of this domain would be expected to interfere with binding of the ubiquitin ligase Itch, ${ }^{75}$ thus providing a mechanistic explanation for the observed role of Pin1 in p73 stabilization. ${ }^{68}$ Given the similar effects exerted on p53 and p73, Pin1 may well represent a common mediator for cooperative activity among the p53 family members.
Pin1 is also controlled by E2F1 and induced during cell cycle progression. ${ }^{76,77}$ Moreover, phosphorylation events regulate both its nuclear localization and substrate binding capability (reviewed in Wulf et $a l^{59}$ ), while recently its ubiquitin-mediated degradation has been found to be inhibited by mitotic signals through Polo-like Kinase1 (Plk1). ${ }^{78} \mathrm{Plk} 1$ is overexpressed in many tumors and this may contribute to the increased levels of Pin1 observed in several cancers. Deregulation of Pin1 can therefore contribute to cancer progression, but this must be reconciled with its role as a regulator of $p 53$ and $p 73$. About $50 \%$ of tumors contain mutant versions of $\mathrm{p} 53$ that may contribute to tumor aggressiveness, and this may be in part due to ablation of p73 functions. Interestingly, Pin1 is able to interact with mutant p53 proteins, which implies that mutant p53 is already phosphorylated on the Pin1 consensus sites. The observation that Pin1 is able to bind mutant $\mathrm{p} 53$ raises the exciting possibility that Pin1 could regulate mutant p53 prooncogenic activities by controlling its ability to trans-activate certain promoters or to interact with specific proteins. Pin 1 modulates the physiological functions of $p 73 ;{ }^{68}$ however in the context of a tumor cell, where signaling pathways are deregulated and p53 is mutated, Pin1 could contribute to oncogenesis by enhancing the interaction between mutant p53 and p73.

Although more work is required to support all these hypotheses, we can view Pin1, under physiological conditions as a fine tuner of the p53 protein family network, while during the transformation process it can change its role becoming a dangerous global amplifier of signaling pathways and thus contributing to cancer progression.

\section{Coordinating Life and Death}

In addition to trying to understand how each individual p53binding protein contributes to the regulation of the p53 pathway, there is a great need to understand how they are all coordinated. This is an extremely difficult task because of the complexity of the interactions between p53 and its many partner proteins (Table 1). However, with respect to those p53-binding proteins discussed in this review, it is possible to make some attempt at coordination. One possible scenario is outlined below (Figure 5).

E2F family members regulate normal cell cycle progression. When bound to $p R b$, a transient $G_{1} / S$ arrest occurs, which is overcome with a proliferative signal as $\mathrm{pRb}$ becomes phosphorylated. The unbound E2F proteins can now bind p53, freeing up cyclin $A$ and causing retention of p53 (phosphorylated on Ser315) in the nucleus (Figure 1), poised presumably to transactivate its target genes. As described above, this would be transient and cyclic. At the same time, YB1 might be shunted into the nucleus dependending on the level of p53 and Akt activity, and possibly on cell cycle phase. This would dampen p53's apoptotic response, but still allow its cell cycle checkpoint activity and therefore a measure of stress responsiveness. Thus, both YB1 and E2F would finetune p53 activity under normal conditions.

If cells are exposed to genotoxic stress, p53 phosphorylation would increase allowing Pin1 to stabilize an energetically unfavorable conformation. p53 could then interact more 


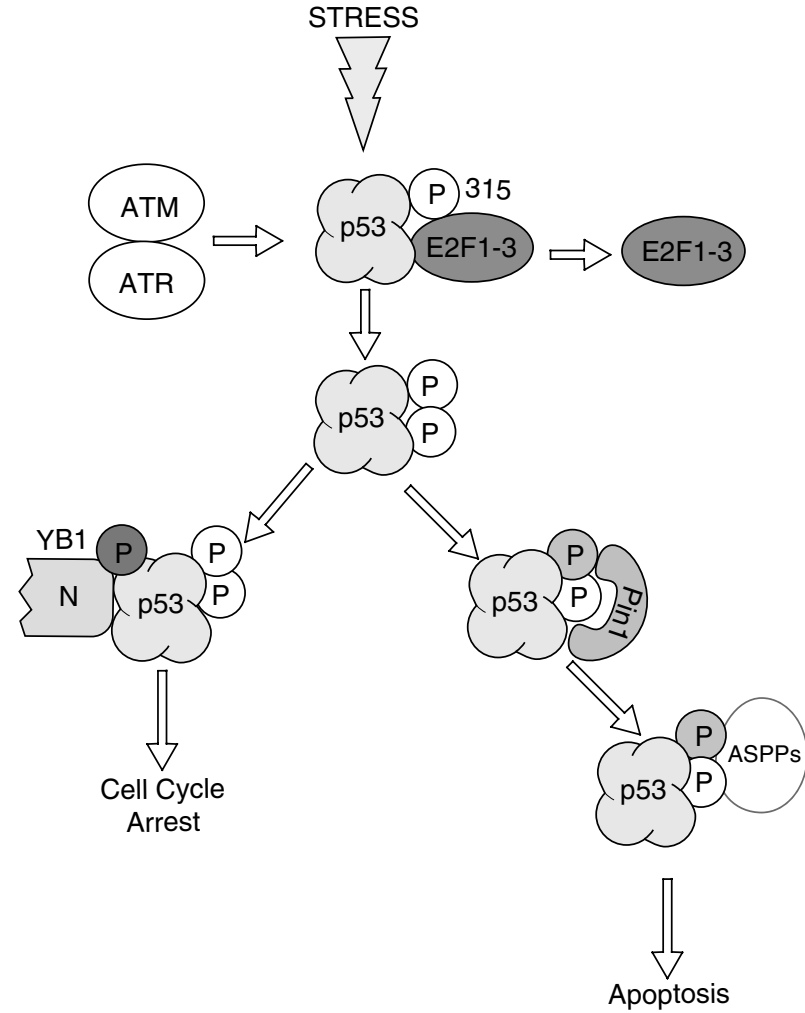

Figure 5 Coordination of cell cycle arrest and apoptosis. p53 activity is regulated by cell cycle-related kinases and E2F family members throughout the cell cycle as in Figure 1. Occasional spikes of p53 might also provoke nuclear translocation of YB1 that would moderate the p53 response. Upon stress signalling such as with DNA damage, different kinases phosphorylate p53 allowing it to be stabilized by Pin1. This would stimulate ASPP binding to p53 and nuclear translocation of YB1. Depending on the balance between these two protein sets, p53-dependent cell cycle arrest (favored by YB1) or apoptosis (favoured by ASPP) would ensue

efficiently with the core transcriptional machinery to transactivate more target genes. This would result in more YB1 translocating to the nucleus, transactivation of $\mathrm{p} 21^{\text {Waf1/Cip } 1 \text {, }}$ and a cell cycle arrest, while inhibiting apoptosis (Figure 3 ). Further signalling to Pin1 (by chronic or severe stress or other signal) would allow Mdm2 detachment and might provoke ASPPs to bind p53 (Figure 4). This might inhibit YB1 (yet to be shown, but suggested by a requirement for the polyproline domain of p53 for YB1 nuclear translocation) and at the same time direct p53 to apoptotic promoters, thus achieving a maximal p53 response. Alternatively, the outcome of the p53 response might be determined by the relative concentrations of YB1 and ASPP proteins. Experiments with knockout mice will elucidate these issues.

This is just one of several scenarios that attempts to link the above p53 regulators in a coordinated manner. It does of course ignore many other known and well-studied p53binding proteins such as are shown in Table 1. Nonetheless, it does illustrate that it is possible to think about networks of regulated protein interactions rather than just individual protein-protein interactions taken in isolation. Clearly, there is still much to be learnt (see Levine et al. ${ }^{79}$ in this issue), but network thinking should help to understand how the many inputs affecting p53 functions are regulated.

\section{Acknowledgements}

We apologize to all colleagues whose work has not been cited owing to space limitations. We thank F. Mantovani, J. Girardini, C. Homer, and W. Ma for useful discussions on this manuscript and for help with its preparation. The GDS laboratory is supported by funds from Associazione Italiana per la Ricerca sul Cancro (AIRC) and the Association for International Cancer Research UK (AICR); the XL laboratory by the Cancer Research UK; and the AWB laboratory by the Health Research Council and Cancer Society of NZ.

\section{References}

1. Prives $C$ and Hall PA (1999) The p53 pathway. J. Path. 187: 112-126.

2. Perrem K, Rayner J, Voss $T$, Sturzbecher $H$, Jackson $P$ and Braithwaite $A$ (1995) p53 represses SV40 transcription by preventing formation of transcription complexes. Oncogene 11: 1299-1307.

3. Zilfou J, Hoffman WH, Sank M, George DL and Murphy M (2001) The corepressor mSin3a interacts with the proline-rich domain of p53 and protects p53 from proteasome mediated degradation. Mol. Cell. Biochem. 21: 3974-3985.

4. Braithwaite $A$, Royds $J$ and Jackson $P(2005)$ The p53 story: layers of complexity. Carcinogenesis 26: 1161-1169.

5. Logan N, Graham A, Zhao X, Fisher R, Maiti B, Leone G and La Thangue NB (2005) E2F-8: an E2F family member with a similar organization of DNAbinding domains to E2F-7. Oncogene 24: 5000-5004.

6. Loughran $\mathrm{O}$ and La Thangue NB (2002) E2F proteins. Curr. Biol. 12: R377.

7. O'Connor DJ, Lam EW, Griffin S, Zhong S, Leighton LC, Burbidge SA and Lu X (1995) Physical and functional interactions between p53 and cell cycle co-operating transcription factors, E2F1 and DP1. EMBO J. 14: 6184-6192.

8. Hsieh JK, Yap D, O'Connor DJ, Fogal V, Fallis L, Chan F, Zhong S and Lu X (2002) Novel function of the cyclin A binding site of E2F in regulating p53induced apoptosis in response to DNA damage. Mol. Cell. Biol. 22: 78-93.

9. Fogal V, Hsieh JK, Royer C, Zhong S and Lu X (2005) Cell cycle-dependent nuclear retention of $\mathrm{p} 53$ by E2F1 requires phosphorylation of $\mathrm{p} 53$ at Ser315. EMBO J. 24: 2768-2782.

10. Sakaguchi K, Sakamoto H, Lewis MS, Anderson CW, Erickson JW, Appella E and Xie D (1997) Phosphorylation of serine 392 stabilizes the tetramer formation of tumor suppressor protein p53. Biochemistry 36: 10117-10124.

11. Price B, Hughes-Davies $L$ and Park $S$ (1995) cdk2 kinase phosphorylates serine315 of human p53 in vitro. Oncogene 11: 73-80.

12. Wang $Y$, Schwedes J, Parks D, Mann K and Tegtmeyer P (1995) Interaction of p53 with its concensus DNA-binding site. Mol. Cell. Biol. 15: 2157-2165.

13. Katayama H, Sasai K, Kawai H, Yuan ZM, Bondaruk J, Suzuki F, Fujii S, Arlinghaus RB, Czerniak BA and Sen S (2004) Phosphorylation by aurora kinase $A$ induces Mdm2-mediated destabilization and inhibition of p53. Nat. Genet. 36: 55-62.

14. DeGregori J, Kowalik T and Nevins JR (1995) Cellular targets for activation by the E2F1 transcription factor include DNA synthesis- and G1/S-regulatory genes. Mol. Cell. Biol. 15: 4215-4224.

15. Leone G, DeGregori J, Jakoi L, Cook JG and Nevins JR (1999) Collaborative role of E2F transcriptional activity and G1 cyclindependent kinase activity in the induction of S phase. Proc. Natl. Acad. Sci. USA 96: 6626-6631.

16. Girard F, Fernandez A and Lamb N (1995) Delayed cyclin A and B1 degradation in non-transformed mammalian cells. J. Cell Sci. 108: 2599-2608.

17. Li Y, Jenkins CW, Nichols MA and Xiong Y (1994) Cell cycle expression and p53 regulation of the cyclin-dependent kinase inhibitor p21. Oncogene 9: 2261-2268.

18. David-Pfeuty T, Chakrani F, Ory K and Nouvian-Dooghe $Y$ (1996) Cell cycledependent regulation of nuclear p53 traffic occurs in one subclass of human tumor cells and in untransformed cells. Cell Growth Differ. 7: 1211-1225.

19. Tolbert D, Lu X, Yin C, Tantama M and Van Dyke T (2002) p19(ARF) is dispensable for oncogenic stress-induced p53-mediated apoptosis and tumor suppression in vivo. Mol. Cell. Biol. 22: 370-377.

20. Bates S, Phillips AC, Clark PA, Stott F, Peters G, Ludwig RL and Vousden KH (1998) p14ARF links the tumour suppressors RB and p53. Nature 395: 124-125. 
21. Stott FJ, Bates S, James MC, McConnell BB, Starborg M, Brookes S, Palmero I, Ryan K, Hara E, Vousden KH and Peters G (1998) The alternative product from the human CDKN2A locus, $\mathrm{p} 14^{\mathrm{ARF}}$, participates in a regulatory feedback loop with p53 and MDM2. EMBO J. 17: 5001-5014.

22. O'Connor DJ and Lu X (2000) Stress signals induce transcriptionally inactive E2F-1 independently of p53 and Rb. Oncogene 19: 2369-2376.

23. Fogal V, Kartasheva NN, Trigiante G, Llanos S, Yap D, Vousden KH and Lu X (2005) ASPP1 and ASPP2 are new transcriptional targets of E2F. Cell Death Differ. 12: 369-376.

24. Stevens $C$ and La Thangue $N$ (2004) The emerging role of E2F-1 in the DNA damage response and checkpoint control. DNA Repair 3: 1071-1079.

25. Samuels-Lev Y, O'Connor DJ, Bergamaschi D, Trigiante G, Hsieh JK, Zhong S, Campargue I, Naumovski L, Crook T and Lu X (2001) ASPP proteins specifically stimulate the apoptotic function of p53. Mol. Cell 8: 781-794.

26. Bergamaschi D, Samuels-Lev Y, O'Neil n, Trigiante G, Crook T, Hsieh JK, O'Connor DJ, Zhong S, Compargue I, Tomlinson M, Kuwabara P and Lin X (2003) iASPP oncoprotein is key inhibitor of p53 conserved from worm to human. Nat. Genet. 33: 162-167.

27. Slee EA, Gillotin S, Bergamaschi D, Royer C, Llanos S, Ali S, Jin B, Trigiante G and Lu X (2004) The N-terminus of a novel isoform of human iASPP is required for its cytoplasmic localization. Oncogene 23: 9007-9016.

28. Bergamaschi D, Samuels Y, Jin B, Duraisingham S, Crook T and Lu X (2004) ASPP1 and ASPP2: common activators of p53 family members. Mol. Cell. Biol. 24: $1341-1350$.

29. de Stanchina E, McCurrach ME, Zindy F, Shieh SY, Ferbeyre G, Samuelson AV, Prives C, Roussel MF, Sherr CJ and Lowe SW (1998) E1A signaling to p53 involves the p19(ARF) tumor suppressor. Genes Dev. 12: 2434-2442.

30. Gorina S and Pavletich NP (1996) Structure of the p53 tumor suppressor bound to the ankyrin and SH3 domains of 53BP2. Science 274: 1001-1005.

31. Ryan KM and Vousden KH (1998) Characterization of structural p53 mutants which show selective defects in apoptosis but not cell cycle arrest. Mol. Cell. Biol. 18: 3692-3698.

32. Kohno K, Izumi H, Uchiumi T, Ashizuka M and Kuwano M (2003) The pleiotropic functions of the Y-box-binding protein, YB-1. BioEssays 25: 691-698.

33. Wolffe AP (1994) Structural and functional properties of the evolutionarily ancient $Y$-box family of nucleic acid binding proteins. BioEssays 16: 245-251.

34. Yu J, Deng M, Medvedev S, Yang J, Hecht NB and Schultz RM (2004) Transgenic RNAi-mediated reduction of MSY2 in mouse oocytes results in reduced fertility. Dev. Biol. 268: 195-206.

35. Yu J, Hecht NB and Schultz RM (2001) Expression of MSY2 in mouse oocytes and preimplantation embryos. Biol. Reprod. 65: 1260-1270.

36. Tafuri SR, Familari M and WolffeA P (1993) A mouse $Y$ box protein, MSY1, is associated with paternal mRNA in spermatocytes. J. Biol. Chem. 268 12213-12220.

37. Koike K, Uchiumi T, Ohga T, Toh S, Wada M, Kohno K and Kuwano M (1997) Nuclear translocation of the Y-box binding protein by ultraviolet irradiation. FEBS Lett. 417: 390-394.

38. Ohga T, Uchiumi T, Makino Y, Koike K, Wada M, Kuwano M and Kohno K (1998) Direct involvement of the YB-1 binding protein YB-1 in genotoxic stressinduced activation of the human multidrug resistace 1 gene. J. Biol. Chem. 273 5997-6000.

39. Stein U, Jurchott K, Walther W, Bergmann S, Schlag PM and Royer HD (2001) Hyperthermia-induced nuclear translocation of transcription factor YB-1 leads to enhanced expression of multidrug resistance-related $A B C$ transporters. J. Biol. Chem. 30: 28562-28569.

40. Sorokin AV, Selyutina AA, Skabkin MA, Guryanov SG, Nazimov IV, Richard C, Th'ng J, Yau J, Sorensen PH, Ovchinnikov LP and Evdokimova V (2005) Proteasome-mediated cleavage of the $\mathrm{Y}$-box-binding protein 1 is linked to DNA-damage stress response. EMBO J. 24: 3602-3612.

41. Janz M, Harbeck N, Dettmar P, Berger U, Schmidt A, Jurchott K, Schmitt M and Royer HD (2002) Y-box factor YB-1 predicts drug resistance and patient outcome in breast cancer independent of clinically relevant tumor biologic factors HER2, UPA and PAI-1. Int. J. Cancer 97: 278-282.

42. Bargou RC, Jurchott K, Wagener C, Bergmann S, Metzner S, Bommert K, Mapara MY, Winzer KJ, Dietel M, Dorken B and Royer HD (1997) Nuclear localization and increased levels of transcription factor YB-1 in primary human breast cancers are associated with intrinsic MDR1 gene expression. Nat. Med. 3: $447-450$
43. Berquin IM, Pang B, Dziubinski ML, Scott LM, Chen YQ, Nolan GP and Ethier SP (2005) Y-box-binding protein 1 confers EGF independence to human mammary epithelial cells. Oncogene 24: 3177-3186.

44. Nicholson R, Gee J and Harper M (2001) EGFR and cancer prognosis. Eur. J. Cancer 37: S9-S15.

45. Bergmann S, Royer-Pokora B, Fietze E, Jurchott K, Hildebrandt B, Trost D, Leenders F, Claude JC, Theuring F, Bargou R, Dietel M and Royer HD (2005) YB-1 provokes breast cancer through the induction of chromosomal instability that emerges from mitotic failure and centrosome amplification. Cancer Res. 65: 4078-4087.

46. Sutherland BW, Kucab J, Wu J, Lee C, Cheang MC, Yorida E, Turbin D, Dedhar S, Nelson C, Pollak M, Leighton Grimes H, Miller K, Badve S, Huntsman D, Blake-Gilks C, Chen M, Pallen CJ and Dunn SE (2005) Akt phosphorylates the $\mathrm{Y}$-box binding protein 1 at Ser102 located in the cold shock domain and affects the anchorage-independent growth of breast cancer cells. Oncogene 24: 4281-4292.

47. Okamoto $T$, Izumi $H$, Imamura $T$, Takano $H$, Ise $T$, Uchiumi $T$, Kuwano $M$ and Kohno K (2000) Direct interaction of p53 with the Y-box binding protein, YB-1: a mechanism for regulation of human gene expression. Oncogene 19: 6194-6202.

48. Lasham A, Moloney S, Hale T, Homer C, Zhang YF, Murison JG, Braithwaite AW and Watson $J(2003)$ The Y-box binding protein YB1 is a potential regulator of the p53 tumor suppressor. J. Biol. Chem. 278: 35516-35523.

49. Gartel A and Tyner A (2002) The role of the cyclin-dependent kinase inhibitor p21 in apoptosis. Mol. Cancer Ther. 1: 639-649.

50. Homer C, Knight DA, Hananeia L, Sheard P, Risk J, Lasham A, Royds JA and Braithwaite AW (2005) Y-box factor YB1 controls p53 apoptotic function. Oncogene 24: 8314-8325.

51. Zhang YF, Homer C, Edwards SJ, Hananeia L, Lasham A, Royds J, Sheard P and Braithwaite AW (2003) Nuclear localization of Y-box factor YB1 requires wild-type p53. Oncogene 22: 2782-2794.

52. Jurchott K, Bergmann S, Stein U, Walther W, Janz M, Manni I, Piaggio G, Fietze E, Dietel M and Royer HD (2003) YB-1 as a cell cycle-regulated transcription factor facilitating cyclin $\mathrm{A}$ and cyclin $\mathrm{B} 1$ gene expression. J. Biol. Chem. 278: 27988-27996.

53. Raffetseder U, Frye B, Rauen T, Jurchott K, Royer HD, Jansen PL and Mertens PR (2003) Splicing factor SRp30c interaction with Y-box protein-1 confers nuclear YB-1 shuttling and alternative splice site selection. J. Biol. Chem. 278: 18241-18248.

54. Sakura H, Maekawa T, Imamoto F, Yasuda K and Ishii S (1988) Two human genes isolated by a novel method encode DNA-binding proteins containing a common region of homology. Gene 73: 499-507.

55. En-Nia A, Yilmaz E, Klinge U, Lovett DH, Stefanidis I and Mertens PR (2005) Transcription factor YB-1 mediates DNA polymerase alpha gene expression. J. Biol. Chem. 280: 7702-7711.

56. Lasham A, Lindridge E, Rudert F, Onrust R and Watson J (2000) Regulation of the human fas promoter by $\mathrm{YB}-1$, Puralpha and AP-1 transcription factors. Gene 252: 1-13.

57. Lu ZH, Books JT and Ley TJ (2005) YB-1 is important for late-stage embryonic development, optimal cellular stress responses, and the prevention of premature senescence. Mol. Cell. Biol. 25: 4625-4637.

58. Mantovani F, Gostissa M, Collavin L and Del Sal G (2004) KeePin' the p53 family in good shape. Cell Cycle 3: 905-911.

59. Wulf G, Finn G, Suizu F and Lu KP (2005) Phosphorylation-specific prolyl isomerization: is there an underlying theme? Nat. Cell Biol. 7: 435-441.

60. Yeh $\mathrm{E}$, Cunningham M, Arnold H, Chasse D, Monteith T, Ivaldi G, Hahn WC Stukenberg PT, Shenolikar S, Uchida T, Counter CM, Nevins JR, Means AR and Sears $R$ (2004) A signalling pathway controlling c-Myc degradation that impacts oncogenic transformation of human cells. Nat. Cell. Biol. 6: 308-318.

61. Wulf GM, Liou YC, Ryo A, Lee SW and Lu KP (2002) Role of Pin1 in the regulation of $p 53$ stability and p21 transactivation, and cell cycle checkpoints in response to DNA damage. J. Biol. Chem. 277: 47976-47979.

62. Zacchi P, Gostissa M, Uchida T, Salvagno C, Avolio F, Volinia S, Ronai Z, Blandino G, Schneider C and Del Sal G (2002) The prolyl isomerase Pin1 reveals a mechanism to control p53 functions after genotoxic insults. Nature 419: 853-857.

63. Sun XF, Johannsson O, Hakansson S, Sellberg G, Nordenskjold B, Olsson H and Borg A (1996) A novel p53 germline alteration identified in a late onset breast cancer kindred. Oncogene 13: 407-411. 
64. Berger M, Stahl N, Del Sal G and Haupt Y (2005) Mutations in proline 82 of $p 53$ impair its activation by Pin1 and Chk2 in response to DNA damage. Mol. Cell. Biol. 25: 5380-5388.

65. Xirodimas DP, Saville MK, Bourdon JC, Hay RT and Lane DP (2004) Mdm2mediated NEDD8 conjugation of p53 inhibits its transcriptional activity. Cell 118: 83-97.

66. Dornan D, Wertz I, Shimizu H, Arnott D, Frantz GD, Dowd P, O'Rourke K Koeppen $\mathrm{H}$ and Dixit VM (2004) The ubiquitin ligase COP1 is a critical negative regulator of p53. Nature 429: 86-92.

67. Leng RP, Lin Y, Ma W, Wu H, Lemmers B, Chung S, Parant JM, Lozano G, Hakem R and Benchimol S (2003) Pirh2, a p53-induced ubiquitin-protein ligase, promotes p53 degradation. Cell 112: 779-791.

68. Mantovani F, Piazza S, Gostissa M, Strano S, Zacchi P, Mantovani R, Blandino $G$ and Del Sal G (2004) Pin1 links the activities of c-Abl and p300 in regulating p73 function. Mol. Cell 14: 625-636.

69. Costanzo A, Merlo P, Pediconi N, Fulco M, Sartorelli V, Cole PA, Fontemaggi G, Fanciulli M, Schiltz L, Blandino G, Balsano C and Levrero M (2002) DNA damage-dependent acetylation of p73 dictates the selective activation of apoptotic target genes. Mol. Cell 9: 175-186

70. Bulavin DV, Saito S, Hollander MC, Sakaguchi K, Anderson CW, Appella E and Fornace Jr AJ (1999) Phosphorylation of human p53 by p38 kinase coordinates $\mathrm{N}$-terminal phosphorylation and apoptosis in response to UV radiation. EMBO J. 18: $6845-6854$

71. D'Orazi G, Cecchinelli B, Bruno T, Manni I, Higashimoto Y, Saito S, Gostissa M, Coen S, Marchetti A, Del Sal G, Piaggio G, Fanciulli M, Appella E and Soddu S (2002) Homeodomain-interacting protein kinase-2 phosphorylates p53 at Ser 46 and mediates apoptosis. Nat. Cell Biol. 4: 11-19.
72. Flores ER, Tsai KY, Crowley D, Sengupta S, Yang A, McKeon F and Jacks $T$ (2002) p63 and p73 are required for p53-dependent apoptosis in response to DNA damage. Nature 416: 560-564.

73. Irwin MS, Kondo K, Marin MC, Cheng LS, Hahn WC and Kaelin Jr WG (2003) Chemosensitivity linked to p73 function. Cancer Cell 3: 403-410.

74. Strano S, Monti O, Pediconi N, Baccarini A, Fontemaggi G, Lapi E, Mantovani F, Damalas A, Citro G, Sacchi A, Del Sal G, Levrero M and Blandino $G$ (2005) The transcriptional coactivator Yes-associated protein drives p73 gene-target specificity in response to DNA damage. Mol. Cell 18: 447-459.

75. Rossi M, De Laurenzi V, Munarriz E, Green DR, Liu YC, Vousden KH, Cesareni $G$ and Melino $G$ (2005) The ubiquitin-protein ligase Itch regulates p73 stability. EMBO J. 24: 836-848.

76. Ryo A, Liou YC, Wulf G, Nakamura M, Lee SW and Lu KP (2002) PIN1 is an E2F target gene essential for Neu/Ras-induced transformation of mammary epithelial cells. Mol. Cell. Biol. 22: 5281-5295.

77. You H, Zheng H, Murray SA, Yu Q, Uchida T, Fan D and Xiao ZX (2002) IGF-1 induces Pin1 expression in promoting cell cycle S-phase entry. J. Cell. Biochem. 84: 211-216.

78. Eckerdt F, Yuan J, Saxena K, Martin B, Kappel S, Lindenau C, Kramer A Naumann S, Daum S, Fischer G, Dikic I, Kaufmann M and Strebhardt K (2005) Polo-like kinase 1-mediated phosphorylation stabilizes Pin1 by inhibiting its ubiquitination in human cells. J. Biol. Chem. 280: 36575-36583.

79. Levine A, Hu W and Feng Z (2006) The p53 pathway: what questions remain to be explored? Cell Death Differ. 13: 1027-1036.

80. Keller DM, Zeng SX and Lu H (2003) Interaction of p53 with cellular proteins. In Walker J (ed) p53 protocols. (Totowa: Humana Press Inc.) pp. 121-133. 